\title{
Youth Sport Practice Model Gets More Kids Active with More Time Practicing Skills Un modelo de entrenamiento deportivo para aumentar los niveles de actividad de los jóvenes y de tiempo de práctica de habilidades

\author{
MichaelA. Kanters*, Thomas L. McKenzie**, Michael B. Edwards*, Jason N. Bocarro*, Matthew T. Mahar***, Ken \\ Martel****, Camilla Hodge*
} \\ *NC State University, **San Diego State University, ***East Carolina, ****USA Hockey
}

\begin{abstract}
Due to the increasing number of children participating in sport, sport clubs and organizations have been identified as an important setting to facilitate physical activity and health promotion. The purpose of this study was to examine whether new national policies for sport practice increases physical activity time without compromising skill development time. Two comparative samples of youth sport leagues with contrasting sport practice models were evaluated for one year. Eighty-two recreational league hockey practices (ages 9-10). Of the practices, 43 used the new approach while 39 operated under a traditional structure. Momentary time sampling was used to measure player physical activity levels and the practice context in which they occur. A Metabolic Equivalent of Task (MET) score was calculated for each practice. Participants spent $44 \%$ of practice time engaged in sedentary activities, 33\% in moderate physical activity, and 23\% in vigorous physical activity. While individual minutes in MVPA and MET scores did not differ significantly between the practice types, new model practices provided overall higher MET hours than traditional practices. New model practices also accommodated approximately 60\% more players while having twice as many coaches, a lower player-to-coach ratio, higher percentage of time in vigorous physical activity, and more time dedicated to skill drills/activities. Findings suggest sport practices can be structured to facilitate high levels of physical activity for more children without compromising attention to skill development and instruction.
\end{abstract}

Keywords. children's sport, physical activity, sport practice structure, skill development

Resumen. Objetivo: Debido al creciente número de niños que participan en el deporte, los clubes y organizaciones deportivas han sido identificados como un marco importante para facilitar la actividad física y promoción de la salud. El objetivo de este estudio fue examinar si las nuevas políticas nacionales para la práctica del deporte aumentan el tiempo de actividad física sin comprometer el tiempo de desarrollo de habilidades. Se evaluaron durante un año dos muestras comparativas de las ligas deportivas juveniles con modelos contrapuestos de entrenamientos en el deporte. Métodos: Ochenta y dos practicantes a nivel recreativo de la liga de hockey (edades entre 9-10 años). De los entrenamientos, 43 utilizaron el nuevo enfoque mientras que en 39 se trabajó con una estructura tradicional. El muestreo de tiempo momentáneo se utilizó para medir los niveles de actividad física del jugador y el contexto de la práctica en que se producen. Se calculó la puntuación de un equivalente metabólico de tareas (MET) de cada entrenamiento. Resultados: Los participantes dedicaron un 44\% del tiempo de la práctica a actividades sedentarias, un 33\% en actividad física moderada y el 23\% en actividad física vigorosa. Mientras los minutos individuales en AFMV y puntuaciones en MET no difieren significativamente entre los tipos de entrenamiento, los entrenamientos en el nuevo modelo proporcionan valores superiores de MET que los entrenamientos tradicionales. Los entrenamientos del nuevo modelo también acomodan aproximadamente un $60 \%$ más de jugadores al tener el doble de entrenadores, un menor ratio de jugador a entrenador, mayor porcentaje de tiempo en actividades físicas vigorosas, y más tiempo dedicado al desarrollo de ejercicios/actividades. Conclusiones: Los resultados sugieren que los entrenamientos deportivos pueden ser estructurados para facilitar altos niveles de actividad física para más niños sin comprometer la atención sobre el desarrollo de habilidades y la enseñanza.

Palabras claves. deporte en niños, actividad física, estructura práctica deportiva, desarrollo de habilidades.

\section{Introduction}

Current recommendations by the U.S. Department of Health and Human Services (USDHHS)(U.S. Department of Health and Human Services, 2008) call for children to accumulate at least 60 minutes of physical activity (PA) daily, most of which should be at moderate to vigorous levels (MVPA). The majority of U.S. children, however, do not meet these guidelines (Troiano et al., 2007). A third of adults and four-fifths of adolescents do not reach public health guidelines for recommended levels of physical activity. Furthermore, children's leisure time physical activity (LTPA) not only remains low but declines with age (Hallal et al., 2012, Nader et al., 2008, U.S. Department of Health and Human Services, 2008).

The USDHHS has recommended three types of physical activity: aerobic activity to improve heart and breathing function (e.g., brisk walking, running), muscle strengthening (e.g., gymnastics, push-ups), and bone strengthening (e.g., jumping rope)(U.S. Department of Health and Human Services, 2008). The USDHHS and American Academy of Pediatrics have identified organized sports as a mechanism for children to obtain physical activity in an environment where risks of participation can be controlled (Council on Sports Medicine and Fitness and Council on School Health, 2006). With nearly 44 million children participating in organized sports across the nation (National Council of Youth Sports, 2008), youth sport programs help a significant number of children in obtaining recommended amounts of physical activity. Furthermore,

Fecha recepción: 30-09-14- Fecha envío revisores: 30-09-14- Fecha de aceptación: 15-11-14 Michael Kanters mkanters@ncsu.ed children participate in organized sports for an average of five years (National Council of Youth Sports, 2008)so community sport providers are well positioned to increase children's physical activity levels.

Research connecting youth sport participation and physical activity is both limited and equivocal. Several studies have shown participation in organized sport to be associated with higher levels of physical activity (Guagliano et al., 2013, Mota \& Esculcas, 2002, Pate R et al., 2000, Pfeiffer et al., 2006, Sacheck et al., 2011) For example, Katzmarzyk and Malina (Katzmarzyk et al., 2001), reported that 12 to 14 year-old boys and girls acquired approximately $60 \%$ of their daily MVPA during organized sports. However, similar to most other studies using selfreport measures, there were concerns about children's ability to accurately recall the duration and intensity of physical activity (Sallis, 1991). Recent studies using objective measures of physical activity (i.e., accelerometers) have found that children engaged in MVPA between $33-46 \%$ of the time during sport practices or games and that there was a high percentage of inactivity time (Guagliano et al., 2013, Sacheck et al., 2011). These studies have also found the amounts of MVPA accrued during sport participation did not happen during non-sport days and was replaced with low-intensity and sedentary activities. This is consistent with other research indicating that children are unlikely to compensate for missed physical activity resulting from sports (Dale et al., 2000). Therefore, while youth sport has the potential to increase recommended amounts of physical activity, it may also be effective in reducing bouts of inactivity or sedentary behavior.

Although children are typically more active on youth sport days, it is not clear how much MVPA they get during practices or how efficiently sport practice time is used. For example, one study that used direct observation methods found children were inactive during $43 \%$ of 
practice time (Katzmarzyk et al., 2001) and another reported that 52\% of sport time was spent in either sedentary or light intensity activity (Wickel \& Eisenmann, 2007). Similarly, Leek et al.(Leek et al., 2011) found fewer than $25 \%$ of youth sport participants obtained the recommended 60 minutes of daily MVPA during practices. Sport practices also tend to over emphasize skill and competition strategies during instructional time, thereby limiting the efficient use of practice facilities and the amount of time children engage in MVPA. Therefore, although organized sports may increase physical activity among youth, its full potential as a strategy to increase children's overall physical activity may be limited by policies and traditional paradigms that govern the structure and delivery of sport practices (Leek et al., 2011).

Although youth sport practices have been identified as a setting to facilitate greater physical activity among children, there may be concerns about compromising an emphasis on instructional and skill development practice time. Within the sport science literature there is general support for a relationship between time dedicated to deliberate practice and achievement of elite sport status (Deakin \& Cobley, 2003, Starkes et al., 1996). Deliberate practice refers to practice activities with the specific goal of improving performance (Ericsson, 1996). Although there is some reference to the importance of physical activity or physical fitness within the context of long term athlete development (Balyi, 2001), the emphasis during early stages of sport development are on physical literacy and fundamental movement skills (Ford et al., 2011). Therefore, any attempt to modify sport practice structure to accommodate greater time in activities that yield higher MVPAmay be challenged by coaches and youth sport administrators if skill development time is compromised.

The national governing organization of ice hockey in the United States, USA Hockey, has recently taken strides to address the limitations of the traditional model of youth sport delivery that tends to overemphasize competition, limit the number of participants during practice time, and possibly hinder children from engaging in substantial amounts of MVPA during sport practices. With the development and implementation of its American Development Model (ADM) (USA Hockey, 2013), USA Hockey has redesigned the practice structure for their developmental programs to best utilize a constrained and often prohibitively expensive practice facility. By dividing the ice surface into smaller areas and organizing children into smaller groups, more players are accommodated on the ice and coach-to-player instruction interactions are improved. Practice participants move through different stations on the ice to learn different skills or tactics. Ice surface area divisions and designations are determined by the specific skills or concepts being taught and by the age or ability level of the players.

Historically, only one team of 14 to 18 players typically used the entire 17,000 square foot ice surface to themselves. This often results in a significant amount of vacant and wasted space since most of hockey practice drills only require a portion of this space. Not only is this practice structure wasteful of expensive space, it may inhibit player development. Ice hockey is a fast moving sport that often requires quick decisions in a space constrained by opposing players. Practice areas that provide excessive space for drills gives participants too much time to think and maneuver resulting in skill development contradictory to actual game play. The station-based structure of ADM practices accommodates substantially more participants on the same surface at the same time, it requires participants to practice in a more confined space which encourages more effective play in traffic and may help players excel in game play.

The purpose of this study was to assess the physical activity levels and skill development opportunities of children during USA Hockey ADM practices and to compare them to non-ADM practices (i.e., more traditional practices). The station based practice design is believed to minimize bouts of sedentary behavior during practice time and increase time in MVPA without compromising skill development time. ADM practice drills are designed to require minimal instruction time for fewer players resulting in more time engaged in drills and overall physical activity. ADM practice plans, provided by USA Hockey, include detailed descriptions for drill setup and instruction thereby minimizing time dedicated to practice drill instruction and demonstration (Figure 1).

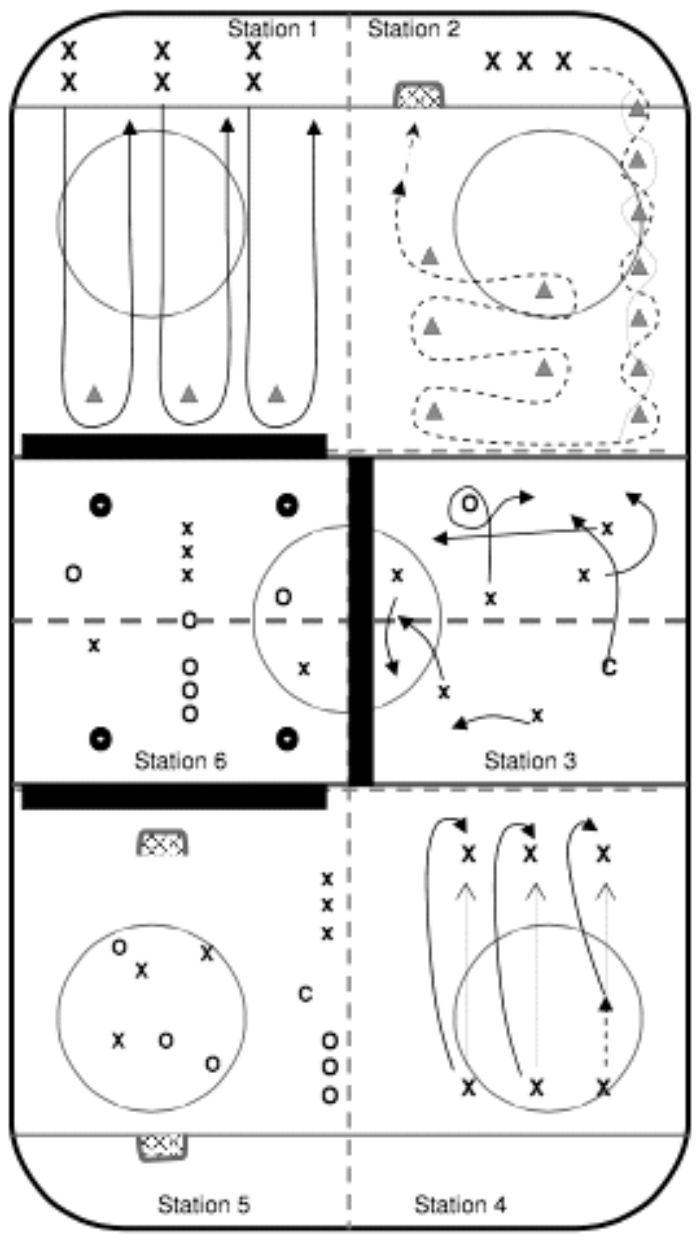

Figure 1. Sample USA Hockey American Development Model practice pl an (USA Hockev. 2014).

\section{Methods}

Ice hockey teams and players were recruited from a southeastern United States youth hockey league 9-10 year old division where the ADM had been fully implemented for a year prior to collection of data. A comparative sample of similar aged teams and players was also recruited from two separate youth hockey organizations in the same metropolitan area that did not currently use ADM. Coaches from each team were sent an email informing them about the purpose and procedures of the study, and asked to notify player parents about their participation in the study. Informed consent was not required as all data collection procedures used unobtrusive observation methods. All study procedures were approved by NC State University's Institutional Review Board for the use of human subjects in research prior to initiation of the study. Data were collected at practices in each of the comparative hockey leagues between February 2012 and February 2013.

\section{Measures}

Systematic Observation of Hockey Opportunities (SOHO) is a direct observation measurement system designed to provide simultaneous objective information on player physical activity levels and the practice context in which they occur (e.g., how practice content is delivered, including time for fitness, skill drills, game play, knowledge transfer, and player/practice management). SOHO uses momentary time sampling and is modeled after the widely used SOFIT (System for Observing Fitness Instruction Time) (McKenzie et al., 1992), but is hockey- 
specific. The following specific outcome variables were measured:

a) Player physical activity levels: number of minutes and \% practice time spent in lying down, sitting, and standing (Sedentary), Walking/ Gliding (Moderate), and Vigorous activity levels.

b) Practice Context: minutes and percent of practice time spent in player/practicemanagement, general knowledge/instruction, fitness, skill drills, game play, and other.

All practice sessions were scheduled for 60 minutes, with the observation of player activity and practice context ranging from 51 to 60 minutes. Following the standard SOFIT protocol four players were randomly selected for observation at each practice. Trained observers were equipped with an audio recording that provided prompts to observe each participant for 10 seconds followed by 10 seconds for recording physical activity level and the practice context.

The PAlevel categories in SOHO have all been validated over the course several studies using a variety of criterion measures such as heart rate, energy expenditure, pedometers, and accelerometers) (e.g., Heath, Coleman, Lensegrav, \& Fallon, 2006; McKenzie, Sallis, Patterson et al, 1991; Pope, Coleman, Gonzalez, \& Heath, 2002; Ridgers et al., 2010; Rowe, van der Mars, Schuldheisz, \& Fox, 2004). The contextual variables all have strong face validity and are defined in the system protocols and training videos.

\section{Reliability}

Field-based inter-observer reliabilities were conducted throughout the study. Equipped with a y-adapter and two earphone jacks, two trained observers independently coded the same participants during the same practice while being paced by a single audio recording. Percent inter-observer agreement (IOA) was calculated for observations of physical activity level and practice context. Seventeen practices were coded for reliability. Overall IOAs were $78 \%$ and $84 \%$ for activity levels and lesson context, respectively. The interclass correlation for independent observers was .95 for physical activity level, and .96 for practice context.

To obtain a summary score, a Metabolic Equivalent of Task(MET) score was calculated for each practice based on multiplying the percentage of time players spent in each activity level (sedentary, moderate, and vigorous) by the corresponding MET value associated with the activity level (Ainsworth et al., 2011). Activity levels were assigned as $1.5=$ Sedentary, 3.0 = Moderate, and 6.0 = Vigorous.

Ordinary least squares (OLS) regression was used to predict the association of ADM on level of physical activity measured in total player minutes in MVPA. Because the ADM is designed to accommodate more children at each practice time, total player minutes in MVPA was a function of observed MVPA x number of practice participants yielding an overall measure of practice MVPA.

\section{Results}

SOHO data were obtained during 82 recreational league hockey practices (ages 9-10) between February 2012 and February 2013. The number of practices per facility ranged from a low of 6 to a high of 23 . Of the practices, 43 used the ADM approach while 39 operated under a traditional structure (non-ADM). Results presented in Table 1 show, overall, players spent $44 \%$ of practice time engaged in sedentary activities (i.e., lying down, sitting, standing), 33\% in moderate physical activity (gliding/walking), and $23 \%$ in vigorous physical activity.

Whileminutes in MVPAand MET scores did not differ significantly between the practice types, ADM practices provided overall higher MET hours than traditional practices. These practices also accommodated approximately $60 \%$ more players while having twice as many coaches, a lower player-to-coach ratio, and a higher percentage of practice time spent in vigorous physical activity than traditional practices.

Overall for the combined ADM and non-ADM groups participants were engaged in skill drills/activities for $55 \%$ of practice time. Other practice time allocations were: knowledge transfer/instruction (14\%),

\begin{tabular}{|c|c|c|c|c|}
\hline Variable & ADM Practice & Traditional Practice & Overall & Effect Size \\
\hline Practice length in minutes & $\begin{array}{c}59.86 * * \\
(1.78)\end{array}$ & $\begin{array}{l}56.39 \\
(4.99)\end{array}$ & $\begin{array}{l}58.21 \\
(4.05)\end{array}$ & 1.05 \\
\hline Number of players & $\begin{array}{l}32.30^{* * *} \\
(8.28)\end{array}$ & $\begin{array}{l}19.39 \\
(9.83)\end{array}$ & $\begin{array}{c}26.16 \\
(11.09)\end{array}$ & 1.43 \\
\hline Number of coaches & $\begin{array}{l}8.56^{* *} \\
(2.62)\end{array}$ & $\begin{array}{c}4.28 \\
(1.83)\end{array}$ & $\begin{array}{l}6.52 \\
(3.12)\end{array}$ & 1.91 \\
\hline Player to Coach Ratio & $\begin{array}{l}3.97^{*} \\
(1.04)\end{array}$ & $\begin{array}{c}4.67 \\
(1.96)\end{array}$ & $\begin{array}{c}4.31 \\
(1.57)\end{array}$ & -0.47 \\
\hline Percent of time in fitness activities & $\begin{array}{c}4.44 \\
(4.54)\end{array}$ & $\begin{array}{l}4.32 \\
(4.17)\end{array}$ & $\begin{array}{l}4.38 \\
(4.35)\end{array}$ & 0.03 \\
\hline Percent of time in skill drills/activities & $\begin{array}{c}57.61 \\
(16.17)\end{array}$ & $\begin{array}{c}53.04 \\
(14.09)\end{array}$ & $\begin{array}{c}55.43 \\
(15.30)\end{array}$ & 0.30 \\
\hline $\begin{array}{l}\text { Percent of time in knowledge } \\
\text { transfer/instruction }\end{array}$ & $\begin{array}{l}16.62^{*} \\
(8.92)\end{array}$ & $\begin{array}{l}11.10 \\
(9.51)\end{array}$ & $\begin{array}{l}13.99 \\
(9.56)\end{array}$ & 0.57 \\
\hline Percent of time in game simul ations & $\begin{array}{c}9.84 \\
(15.71)\end{array}$ & $\begin{array}{c}13.97 \\
(18.87)\end{array}$ & $\begin{array}{c}11.81 \\
(17.19)\end{array}$ & -0.24 \\
\hline $\begin{array}{l}\text { Percent of time in practice management } \\
\text { adivities }\end{array}$ & $\begin{array}{l}10.58^{*} \\
(3.94)\end{array}$ & $\begin{array}{l}15.76 \\
(8.62)\end{array}$ & $\begin{array}{l}13.05 \\
(7.05)\end{array}$ & -0.73 \\
\hline Percent of time players sedentary & $\begin{array}{l}43.83 \\
(7.74)\end{array}$ & $\begin{array}{r}44.81 \\
(11.52)\end{array}$ & $\begin{array}{l}44.42 \\
(9.67)\end{array}$ & -0.10 \\
\hline Percent of time players in moderate PA & $\begin{array}{l}30.79 \\
(9.28)\end{array}$ & $\begin{array}{c}35.19 \\
(13.51)\end{array}$ & $\begin{array}{c}32.89 \\
(11.63)\end{array}$ & -0.39 \\
\hline Percent of time players in vigorous $\mathrm{PA}$ & $\begin{array}{l}25.40^{*} \\
(9.39)\end{array}$ & $\begin{array}{r}20.29 \\
(11.12)\end{array}$ & $\begin{array}{c}22.97 \\
(10.50)\end{array}$ & 0.50 \\
\hline $\begin{array}{l}\text { Minutes in moderate or vigorous physical } \\
\text { activity }\end{array}$ & $\begin{array}{r}33.64 \\
(4.81)\end{array}$ & $\begin{array}{l}31.29 \\
(6.91)\end{array}$ & $\begin{array}{l}32.53 \\
(5.98)\end{array}$ & 0.40 \\
\hline Total player minutes in MVPA & $\begin{array}{c}1087.75 * * \\
(324.04)\end{array}$ & $\begin{array}{c}585.17 \\
(293.68)\end{array}$ & $\begin{array}{c}848.82 \\
(398.35)\end{array}$ & 1.62 \\
\hline Average indi vidual METs & $\begin{array}{l}3.11 \\
(.347)\end{array}$ & $\begin{array}{l}2.95 \\
(.344)\end{array}$ & $\begin{array}{l}3.03 \\
(.386)\end{array}$ & 0.46 \\
\hline Total MET hours & $\begin{array}{l}99.75 * * \\
(26.16)\end{array}$ & $\begin{array}{r}57.03 \\
(29.48)\end{array}$ & $\begin{array}{r}79.43 \\
(35.52)\end{array}$ & 1.54 \\
\hline
\end{tabular}

management, such as drill setup, organizing players (13\%), game simulations/play (13\%), fitness (4\%), and free play (1\%). Acomparison of ADM and non-ADM practices showed ADM practices had more time dedicated to skill drills/activities (57\% vs. 52\%) and knowledge transfer/instruction (17\% vs. $11 \%$ ). Non-ADM practices allocated more time to practice management activities ( $16 \%$ vs. $10 \%$ ) and game simulations (16\% vs. $10 \%)$.

OLS regress results presented in Table 2 show the model estimated that the ADM practice type was associated with an increase of 502.6 player minutes in MVPA. It was also expected that the lower playerto-coach ratio during ADM practices might have an influence on player minutes in MVPA, so a second analysis was conducted controlling for coach to player ratio (Table 3). This model suggested that a higher player-to-coach ratio was associated with more player minutes in MVPA. Thus, controlling for differences in player-to-coach ratio, ADM practice type was associated with an increase of 536 player minutes in MVPA.

OLS regression was also used to predict the association of ADM on level of physical activity measured in MET hours. The model estimated that the ADM practice type was associated with an increase

\begin{tabular}{|c|c|c|c|c|}
\hline \multicolumn{4}{|r|}{ SE. } & \\
\hline Constant & 585.17 & $\overline{--}$ & 49.64 & $<.001$ \\
\hline ADM & 502.57 & 634 & 68.55 & .001 \\
\hline N & & 82 & & \\
\hline$R^{2}$ & & .39 & & \\
\hline \\
\hline \multicolumn{5}{|c|}{$\begin{array}{l}\text { Table } 3 \\
\text { Ordinary Least Squares Regression of player minutes in MVPA by practice type controlling for player- } \\
\text { coach ratio }\end{array}$} \\
\hline & $\underline{\mathrm{B}}$ & Beta & S.E. & $\underline{p}$ \\
\hline Constant & 360.42 & & 113.19 & .002 \\
\hline ADM & 536.03 & .676 & 68.67 & $<.001$ \\
\hline Player-Coach Ratio & 48.11 & 190 & 21.89 & .031 \\
\hline & & 82 & & \\
\hline$R^{2}$ & & .42 & & \\
\hline \multicolumn{5}{|c|}{ Table 4} \\
\hline \multicolumn{5}{|c|}{$\begin{array}{l}\text { Ordinary Least Squares Regression of MET hours by practice type } \\
\text { Ord }\end{array}$} \\
\hline & B & Beta & S.E. & $p$ \\
\hline Constant & 57.03 & -- & 4.56 & $\frac{p}{<.001}$ \\
\hline ADM & 42.72 & .604 & 6.29 & $<.001$ \\
\hline$N$ & & 82 & & \\
\hline$R^{2}$ & & .36 & & \\
\hline \multirow{2}{*}{\multicolumn{5}{|c|}{$\begin{array}{l}\text { Table } 5 \\
\text { Ordinary Least Squares Regression of MET hours by practice type control ling for plaver-coach ratio }\end{array}$}} \\
\hline & & & & \\
\hline & B & Beta & S.E. & \\
\hline Constant & 29.49 & - & 10.15 & .005 \\
\hline ADM & 46.82 & .662 & 6.16 & $<.001$ \\
\hline Player-Coach Ratio & 5.89 & .262 & 1.96 & .004 \\
\hline$N$ & & 82 & & \\
\hline$R^{2}$ & & .43 & & \\
\hline
\end{tabular}


of 42.72 MET hours (Table 4). Again, it was expected that the lower player-to-coach ratio provided during ADM practices may have an influence on MET hours, so a second analysis was conducted controlling for coach to player ratio (Table 4). Interestingly, the model suggested that a higher player-to-coach ratio was associated with increased MET hours. Thus, controlling for differences in player-to-coach ratio, ADM practice type was associated with an increase of 46.82 MET hours.

\section{Discussion}

The USDHHS (U.S. Department of Health and Human Services, 2008) and the American Academy of Pediatrics (Council on Sports Medicine and Fitness and Council on School Health, 2006) both recommend youth sports as an important means of increasing physical activity among children. Research, however, has indicated while children may participate in sport practices lasting 60 minutes or longer, they spend a significant portion of this time being sedentary (Leek et al., 2011, Wickel \& Eisenmann, 2007). In the current study young hockey players were sedentary (i.e., lying down, sitting, standing) 33\% of practice time, but they spent a majority of it in MVPA — substantially more than in other sport settings, including physical education classes. Comparisons with previous studies of physical activity during sport practices suggest participants in youth hockey spend a greater percentage of practice time in MVPA than do participants in baseball/softball and flag football,(Wickel \& Eisenmann, 2007) and about the same amount of practice time in MPVA as participants in soccer (Leek et al., 2011).

Comparisons between practices using USA Hockey's American Development Model (ADM) with those not following the new standardized structure (non-ADM) showed no significant differences in the amount of MVPA accrued by individuals. This was surprising given that ADM practices are generally designed for a wide diversity of skill drills that emphasize continuous movement. Nonetheless, this finding may be due to a 'ceiling effect' generated by the nature of hockey which has a number of 'starts and stops' and the need for players to recover from bursts of highly intense activity. The lack of differences may also be due to the increased number of players in $\mathrm{ADM}$ practices (60\% more) that occupy a space similar in size to that allocated for nonADM practices. As a result, while the ADM practices generated similar amounts of MVPA as did the traditional model, they accommodated about $60 \%$ more children during the same time period. Therefore, the overall public health or energy expenditure effect of ADM practices was substantially greater than non-ADM practices.

While the overall MVPA for both sport practice models were similar, participants in ADM practices spent about 5\% more time in vigorous physical activity. It is recommended that youth participate in 60 minutes or more of physical activity each day, including at least three days per week of vigorous physical activity. The significantly higher levels of vigorous intensity physical activity afforded by the ADM practices compared to non-ADM practices may provide unique health benefits. Limited research evidence suggests that time spent in vigorous intensity physical activity is more highly associated with health benefits (systolic blood pressure, body mass index, waist circumference, and cardiorespiratory endurance) than moderate intensity physical activity (Carson et al., 2013, Hay et al., 2012).

As well as accommodating more players on the ice at one time, the ADM model engaged significantly more coaches. This resulted in a lower player-to-coach ratio, which has the possibility of children getting more individual attention and appropriate prompts and feedback for skill development. The practice context measures showed that while both practice models spent the majority of time in skill development activities, this time was higher in the ADM program. ADM practices also used less time for management activities such as setting up drills and organizing players. Managerial efficiency is extremely important for youth sport delivery because practice facilities are expensive and often limited by both time and money (Evenson \& McGinn, 2004). Additionally, time used in management minimizes valuable skill development time that cannot be replicated in an off-ice environment.
The study is limited by the examination of the ADM program in only one geographic region of the U.S. Application of ADM and its principles are dependent on the policies and practices of individual youth hockey leagues, therefore, the findings of this study may not occur in all ADM programs. Another limitation of this study relates to the design of the ADM program, as ADM coaches were given complete freedom to choose which activities to incorporate into each session. It must be acknowledged that the variety of activities incorporated into ADM sessions likely had differential effects on physical activity outcomes, which was not accounted for in this study. Additionally, the measure of PA through observation does not allow to select the epoch (i.e. the duration of time periods to record activity patterns, such as when using accelerometers).

\section{Conclusion}

In summary, objective methods of assessing physical activity found that young players in these hockey leagues were accruing substantial amounts physical activity during regularly scheduled practices. As well, the data showed that the ADM model facilitated the accrual of MVPA time that is among the highest reported in studies of youth sport participants. More notable, however, is that the ADM helped participants achieve these high MVPA levels while accommodating $60 \%$ more players than the standard coaching model and used a significantly lower player-to-coach ratio. Finally, the primary purpose of any sport practice, especially during the early development years, is creating opportunities for participants to learn and practice skills. The $\mathrm{ADM}$ appears to minimize time wasted on practice management activities while creating more time for skill practice.

Because of the increasing number of children participating in sport, organized sport clubs and organizations have been identified as an important setting to facilitate physical activity and health promotion (Geidne et al., 2013).However, as Geidne et al., in their integrative review of research noted, "to become a health-promoting setting, youth sport organizations need to take a comprehensive approach to activities, aims, and purposes” [p. 281](Geidne et al., 2013). It seems apparent that USA Hockey has developed a framework to facilitate high levels of physical activity for more children without compromising attention to skill development and instruction. The ADM strategies may serve as a model for youth sports seeking to accommodate the increasing demands for participation on constrained practice facilities and time for practice.

\section{References}

Ainsworth, B. E., Leon, A. S., Haskell, W. L., Hermann, S. D., Meckes, N., Bassett, D. R., Tudor-Locke, C., Greer, J. L., Vezina, J. \& Whitt-Glover, M. C. (2011) 2011 compendium of physical activities: A second update of codes and met values. Medicine \& Science in Sports \& Exercise, 43(8), 1575-1581.

Balyi, I. (2001) Sport system building and long-term athlete development in british columbia. Coaches Report, 8(1), 22-28.

Carson, V., Rinaldi, R. L., Tomten, H., Maximova, K., Ball, K. D. C., Majumdar, S. R., Plotnikoff, R. C., Veugelers, P. \& Boule, N. G. (2013) Vigorous physical activity and longitudinal associations with cardiometabolic risk factors in youth. International Journal of Obesity, Advance online publication(

Council on Sports Medicine and Fitness and Council on School Health (2006) Active healthy living: Prevention of childhood obesity through increased physical activity. Pediatrics, 117(5), 1834-1842.

Dale, D., Corbin, C. B. \& Dale, K. S. (2000) Restricting opportunities to be active during school time: Do children compensate by increasing physical activity levels after school? Research Quarterly for Exercise and Sport, 71(3), 240-248.

Deakin, J. M. \& Cobley, S. (2003) A search for deliberate practice: An examination of the practice enviornments in figure skating and volleyall. , in: J. Starkes \& K. A. Ericsson (Eds) Expertperformance in sport: Recentadvances in researchon sportexpertise. Champaign, 
IL, Human Kinetics), 115-135.

Ericsson, K. A. (1996) The road to excellence: The acquisition of expert performance in the arts and sciences, sports and games. , (Mahwah, NJ, Erlbaum).

Evenson, K. R. \& Mcginn, A. P. (2004) Availability of school physical activity facilities to the public in four u.S. Communities. American Journal of Health Promotion, 18(3), 243-250.

Ford, P., De Ste Croix, M., Lloyd, R., Meyers, R., Moosavi, M., Oliver, J., Till, K. \& Williams, C. (2011) The long-term athlete developmentmodel: Physiological evidence and applicaiton. Journal of Sport Sciences, 29(389-402.

Geidne, S., Quennerstedt, M. \& Eriksson, C. (2013) The youth sports club as a health-promoting setting: An integrative review of research. Scandinavian Journal of Public Health, 41(3), 269-83.

Guagliano, J. M., Rosenkranz, R. R. \& Kolt, G. S. (2013) Girls’ physical activity levels during organized sports in australia. Medicine \& Science in Sports \& Exercise, 45(1), 116-22.

Hallal, P. C., Andersen, L. B., Bull, F. C., Guthold, R., Haskell, W. L. \& Ekelund, U. (2012) Global physical activity levels: Surveillance progress, pitfalls, and prospects. Lancet, 380(9838), 247-257.

Hay, J., Maximova, K., Durksen, A., Carson, V., Rinaldi, R. L. \& Torrance, B. (2012) Physical activity intensity and cardiometabolic risk in youth. Archive of Pediatric and Adolescent Medicine, 166(1022-1029.

Heath, E. M., Coleman, K. J., Lensegrav, T., \& Fallon, J. A. (2006). Using momentary time sampling to estimate minutes of physical activity in physical education: Validation of scores for the System for Observing Fitness Instruction Time. Research Quarterly for Exercise and Sport, 77, 142-146.

Katzmarzyk, P., Walker, P. \& Malina, R. (2001) A time-motion study of organized youth sports. Journal of Human Movement Studies, 40(5), 325-334.

Leek, D., Carlson, J. A., Cain, K. L., Henrichon, S., Rosenberg, D., Patrick, K. \& Sallis, J. F. (2011) Physical activity during youth sports practices. Archive of Pediatric and Adolescent Medicine, 165(4), 294-9.

Mckenzie, T. L., Sallis, J. F. \& Nader, P. (1992) Sofit - system for observing fitness instruction time. Journal of Teaching in Physical Education, 11(2), 195-205.

McKenzie, T. L., Sallis, J. F., Patterson, T. L., Elder, J. P., Berry, C. C., Rupp, J. W., . . . Nader, P. R. (1991). BEACHES: An observational system for assessing children's eating and physical activity behaviors and associated events. Journal of Applied Behavior Analysis, 24, 141-151.

Mota, J. \& Esculcas, C. (2002) Leisure-time physical activity behavior: Structured and unstructured choices acccording to sex, age, and level of physical activity. International Journal of Behavioral Medicine, 9(2), 111-121.

Nader, P. R., Bradley, R. H., Houts, R. M., Mcritchie, S. L. \& O’brien, M. (2008) Moderate-to-vigorous physical activity from ages 9 to 15 years. Journal of the American Medical Association, 300(3), 295-305.
National Council of Youth Sports (2008) Report on trends and participation in organized youth sports. Available online at: http:// www.ncys.org/pdfs/2008/2008-ncys-market-research-report.pdf (accessed September 5th 2013).

Pate R, G., T. S., S., L. \& M., D. (2000) Sports participation and healthrelated behaviors among us youth. Archive of Pediatric and Adolescent Medicine, 154(9), 904-911.

Pfeiffer, K. A., Dowda, M., Dishman, R. K., Mciver, K. L., Sirard, J. R., Ward, D. S. \& Pate, R. R. (2006) Sport participation and physical activity in adolescent females across a four-year period. Journal of Adolescent Health, 39(4), 523-9.

Pope, R. P., Coleman, K. J., Gonzalez, E. C., Barron, F. \& Heath, E. M. (2002). Validity of a revised system of observing fitness instruction time (SOFIT). Pediatric Exercise Science, 14, 135-146.

Ridgers, N. D., Stratton, G. \& McKenzie, T. L. (2010). Reliability and validity of the System for Observing Children's Activity and Relationships during Play (SOCARP). Journal of Physical Activity and Health, 7, 17-25.

Rowe, P. J., van der Mars, H., Schuldheisz, J. M., \& Fox, S. (2004). Measuring physical activity in physical education: Validating SOFIT for use with high school students. Journal of Teaching in Physical Education, 23, 235-251.

Sacheck, J. M., Nelson, T. F., Ficker, L., Kafka, T., Kuder, J. \& Economos, C. D. (2011) Physical activity during soccer and its contribution to physical activity recommendations in normal weight and overweight children. Pediatric Exercise Science, 23(2), 281292.

Sallis, J. F. (1991) Self-report measures of children's physical activity. Journal of School Health, 61(215-219.

Starkes, J. L., Deakin, J. M., Allard, F., Hodges, N. \& Hayes. (1996) Deliberate practice in sports: What is it anyway? , in: K. a. E. Erricson (Ed.) The road to excellence: The acquisition of expert performance in the arts and sciences, sports and games. NJ: Erlbaum, Mahwah).

Troiano, R. P., Berrigan, Dodd, K. W., Masse, L. C., Tilert, T. \& Mcdowell, M. (2007) Physical activity in the united states measured by accelerometer. Medicine \& Science in Sports \& Exercise, 40(1), 181-188.

U.S. Department of Health and Human Services (2008) 2008 physical activity guidelines for americans. Available online at: http:// www.health.gov/paguidelines/pdf/paguide.pdf (accessed September 5th 2013).

USA Hockey (2013) American development model website. Available online at: http:/assets.ngin.com/attachments/document/0042/7978/ ADMGuide_2011.pdf (accessed September 5th 2013).

USA Hockey (2014) Adm practice plans. Available online at: http:// www.usahockey.com/page/show/893671-practice-plans (accessed March 21, 2014 2014).

Wickel, E. E. \& Eisenmann, J. C. (2007) Contribution of youth sport to total daily physical activity among 6- to 12-yr-old boys. Medicine \& Science in Sports \& Exercise, 39(9), 1493-500.

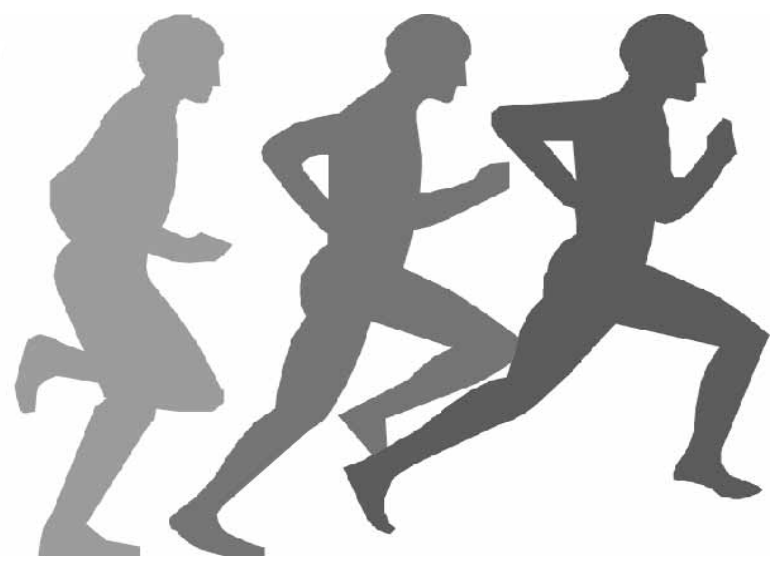

